\title{
Effects of male sexual maturity of reproductive endpoints relevant to DART studies in Wistar Hannover rats
}

\author{
Ikuro Takakura' ${ }^{1}$, Dianne M. Creasy², Ryohei Yokoi ${ }^{1}$, Yukari Terashima ${ }^{1}$, \\ Tomoya Onozato ${ }^{1}$, Yoshimasa Maruyama ${ }^{1}$, Tomonobu Chino', ${ }^{1}$ Toru Tahara ${ }^{1}$, \\ Toru Tamura $^{1}$, Junji Kuroda ${ }^{1}$ and Hiroshi Kusama ${ }^{1}$ \\ ${ }^{1}$ Safety Research Laboratory, R\&D, Kissei Pharmaceuticals Co., Ltd., \\ 2320-1 Maki, Hotaka, Azumino-City, Nagano-Pref. 399-8305, Japan \\ ${ }^{2}$ Huntingdon Life Sciences Co., Ltd., Mettlers Road, East Millstone, New Jersey 08875, USA
}

(Received October 16, 2013; Accepted January 10, 2014)

\begin{abstract}
Wistar Hannover rats have been utilized as one of major strains in regulatory toxicology studies. This study was performed to verify the appropriate age of male sexual maturity in the development and reproductive toxicity (DART) study in Wistar Hannover rats (RccHan:WIST) by comparing reproductive endpoints between 8,10 and 12 weeks of ages. Although fertility showed a tendency toward decrease in 8-week-old males, copulation index was not different among three ages. Testis weights reached a plateau at 10 weeks of age, whereas weights of other reproductive organs developed until 12 weeks of age. Indices of spermatogenesis (sperm motility, number of sperm in the epididymis and testis and contents of morphologically abnormal sperm) showed age-related progress and did not fully develop except for 12-week-old. For histology, epididymal tubules in 8-week-old animals showed immaturity with tall epithelium. At cesarean section, dams mated with 8-week-old males showed high incidence of preimplantation loss and the number of live fetuses was less than 10. In conclusion, although reproductive performance attained maturity by age of 10 weeks, spermatogenesis was not fully established at 10 -weekold, which could result in a low fertility index. Therefore, we recommend that Wistar Hannover male rats at 12-week-old or older are used to conduct DART study properly and evaluate any adverse effects on dams and embryo-fetal development.
\end{abstract}

Key words: Wistar Hannover rat, Sexual maturity, Age, Development and reproductive toxicity study

\section{INTRODUCTION}

The Wistar Hannover (Wistar Han) rat has been used as one of the major strains for conducting nonclinical and chemical safety evaluation programs, particularly in Europe. Recently, this strain was highlighted in many countries including Japan. The Sprague Dawley rat used to be the most commonly used strain, but its progressive decrease in survival rate in 2 year carcinogenicity studies has led to a gradual decline in its use and replacement with the Wistar Han rats. In comparison with the Sprague Dawley rat, the Wistar Han rat has a smaller body weight, an increased survival rate and a lower tumor burden (Weber et al., 2011). For the justification of selecting the rat strain that is to be used in a safety evaluation program, reproductive performance is another important con- sideration, because development and reproductive toxicity (DART) studies are one of the critical components of the regulatory submission. It is important that the strain chosen has good fertility and fecundity, produces an adequate litter size and an equal sex ratio. The age of mating can have a significant impact on reproductive parameters and so it is important to ensure that the animals are fully sexually mature when they mate. There has been some suggestion that male Wistar Han rats attain sexual maturity later than Sprague Dawley rats. For example, the OECD test guideline 422: Combined repeat dose toxicity study with the Reproduction/Developmental screening test, states "The study should be scheduled in such a way that mating begins soon after sexual maturity. This may vary slightly for different strains of rats in different laboratories, e.g. Sprague Dawley rats 10 weeks of age, Wis-

Correspondence: Ikuro Takakura (E-mail: ikuro_takakura@pharm.kissei.co.jp) 
tar rats about 12 weeks of age". However, a recent study that compared a number of reproductive and maturation endpoints in the male Wistar Han rat (Cel:WI(Han)Strain code 273) with the Sprague Dawley rat (Crl:CD(SD) IGS BR), reported very few differences between the two strains (Campion et al., 2013).

The objectives of this study were to evaluate several different reproductive and fertility endpoints in male Wistar Han rats of 8, 10 and 12 weeks of age, with the objective of monitoring sexual maturation and to establish the appropriate age of male Wistar Han rat for mating in a DART study.

\section{MATERIALS AND METHODS}

\section{Animals}

Specific pathogen-free Wistar Hannover rats (RccHan:WIST) were obtained from JLA, Inc. (Saitama, Japan). Thirteen male rats at 7,9 or 11 ages of weeks and 80 female rats at 11 weeks of age were received and acclimated to laboratory conditions for 1 week prior to the start of the study. The rats were housed in individual stainless steel cages $(260 \times 230 \times 180 \mathrm{~mm})$ in a barrier sustained animal room maintained at a room temperature of $23 \pm 2{ }^{\circ} \mathrm{C}$, relative humidity of $60 \pm 10 \%$, and 12-hr light/dark cycle (light on 8:00 a.m. to 8:00 p.m.) with ventilations at 11.1 times per hour. The animals were allowed free access to tap water and a pellet diet (CE-2, CLEA Japan Inc., Tokyo, Japan) during the quarantine, acclimation and study period. This study was performed in strict accordance with the animal welfare bylaws of Safety Research Laboratory, Kissei Pharmaceutical Co., Ltd. The Institutional Animal Care and Use Committee (IACUC) in our institution oversaw the animal management of this study.

\section{Fertility study}

Twelve-week-old females that were in good health and in proestrus stage in the vaginal smear examination were selected for mating. Each of them was cohabited overnight with a 8-, 10- or 12-week-old male (13 males per age group). Successful copulation was defined by the presence of a vaginal plug or sperm in a vaginal smear on the day following cohabitation, with this day being designated as gestation day 0 or postcoitum day 0 . The cohabitation was performed up to twice for each male animal. A male animal was allowed to cohabit with another female only once again if successful copulation was not confirmed at the first cohabitation. At the time of determination of successful copulation, copulatory plug, when available, were collected, counted and weighed. The cop- ulatory plugs collected were preserved in $99.5 \%$ ethanol and air-dried prior to being weighed.

\section{Termination of male animals with successful copulation}

Male rats were weighed and euthanized by carbon dioxide asphyxiation and necropsied on the day of confirmation of successful copulation. The weights of the testes, epididymides, seminal vesicle and prostate were measured. Left testis and left epididymis were fixed in folmaldehyde acetic acid (FA) fixative for 4 days and were then postfixed in 10\% phosphate-buffered formalin (Kuze, 1997). Seminal vesicle and prostate were preserved in $10 \%$ phosphate-buffered formalin. The right testis was used to count testicular spermatid heads. The right epididymis was used to count sperm in caput and caudal epididymis, to observe sperm morphologically and to measure sperm motility parameters.

\section{Preparation of sperm suspension}

Prior to the preparations for sperm suspension, caput and caudal region of right epididymis and right testis were weighed. Following the measument, the right caudal epididymis was placed in $1 \mathrm{ml}$ of Hank's solution containing $0.5 \% \mathrm{BSA}$ at $37^{\circ} \mathrm{C}$ (Klinefelter et al., 1991) and allowed to disperse. After two minutes, a small amount of sperm suspension was collected and prepared for analysis of sperm viability, sperm motility, sperm motion parameters, sperm counts and sperm morphology.

\section{Computer assisted sperm motion analysis (CASA)}

The sperm suspension prepared as described above was analyzed for sperm motility with a HTM-IVOS (Hamilton Thorne Research, Beverly, MA, USA) using a sample chamber (cannula: $100 \mu \mathrm{m}$ deep, $2 \mathrm{~mm}$ wide, Vitro Com Inc., NJ, USA). Two hundred or more sperm per animal were analyzed. Nine sperm motion parameters generated by HTM-IVOS were examined in each sample. The HTM-IVOS setting and definition of parameters measured are shown in Tables 1 and 2, respectively.

\section{Sperm count}

Following the analysis by CASA, the caput and caudal region of right epididymis were dissected, placed in Hank's solution with $0.5 \%$ BSA added at $37^{\circ} \mathrm{C}$ for an hour and allowed to disperse. For right testis, the tunica albuginea was removed from testis and the parenchyma was homogenized with $50 \mathrm{ml}$ of saline containing $0.5 \%$ of Triton X-100 and $0.02 \%$ of sodium azide. The sperm suspension was filtrated through nylon mesh for debris 
Suitable age of Wistar Han male rats for DART study

removal. The aliquot of sperm suspension prepared from the caput and caudal regions of right epididymis and right testis was placed on counting chamber and counted under a microscope for the calculation of the number of sperm per gram of each region.

Table 1. Settings of HTM-IVOS used for sperm motion analysis

\begin{tabular}{ll}
\hline Set up parameter & \\
\hline Frames acquired & 30 \\
Frames rate $(\mathrm{Hz})$ & 60 \\
Minimum contrast & 80 \\
Minimum cell size (pixel) & 7 \\
Minimum static contrast & 15 \\
Straightness $(\mathrm{STR})$, threshold $\left(\mathrm{S}_{0}\right)(\mu \mathrm{m} / \mathrm{sec})$ & 80 \\
Low VAP cutoff $(\mu \mathrm{m} / \mathrm{sec})$ & 20 \\
Medium VAP cutoff $(\mu \mathrm{m} / \mathrm{sec})$, threshold $\left(\mathrm{V}_{0}\right)(\mu \mathrm{m} / \mathrm{sec})$ & 50 \\
Low VSL cutoff $(\mu \mathrm{m} / \mathrm{sec})$ & 30 \\
Head size, non-motile $(\mathrm{pixel})$ & 25 \\
Head intensity, non-motile & 80 \\
Static head size & $0.72-8.82$ \\
Static head intensity & $0.14-1.84$ \\
Static elongation & $0-47$ \\
Temperature set $\left({ }^{\circ} \mathrm{C}\right)$ & 37 \\
\hline
\end{tabular}

\section{Morphological examination of sperm}

The remaining sperm suspension was stained with $0.5 \%$ Eosin Y, smeared onto a slide glass, air-dried overnight, fixed in methanol and examined microscopically (Wryobek and Bruce, 1975). Two hundred spermatozoa in each sample were examined for head, neck and tail morphological abnormalities (Linder et al., 1992). For the classification of sperm morphological abnormalities, Yoshizaki's classification (Yoshizaki et al., 1999) was slightly modified and classified as follows: 1) tailless sperm, 2) no-hook head sperm, 3) amorphous head sperm, 4) sperm with neck abnormalities, 5) sperm with tail abnormalities and 6) other abnormal sperm.

\section{Histology and quantitative evaluation of spermatogenic cells}

Left testis, left epididymis, seminal vesicle and prostate were fixed and processed to paraffin-embedded sections and stained with hematoxylin and eosin or periodic acid-Schiff (PAS). Sections of the testis stained with PAS were subjected for the quantitative evaluation of spermatogenic cells (Matsui et al., 1996). A total of 5 seminiferous tubules per animal were randomly chosen and the numbers of seminiferous epithelial cells in stages II-III, V, VII and XII were counted for analyzing the spermatogenic cycle stage of testicular seminiferous epithelium. The cell types distinguished included spermatogonia, preleptotene spermatocytes, leptotene spermatocytes, zygotene spermatocytes, pachytene spermatocytes, round sperma-

Table 2. Definition of sperm motion parameters generated by HTM- IVOS

\begin{tabular}{|c|c|c|c|}
\hline Parameter & Abbreviation & Unit & Definition \\
\hline Percentage of motile sperm & Motile sperm & $\%$ & Ratio of motile sperm to total number of sperm \\
\hline Average path velocity & VAP & $\mu \mathrm{m} / \mathrm{sec}$ & Average velocity of the smooth sperm path \\
\hline Straight line velocity & VSL & $\mu \mathrm{m} / \mathrm{sec}$ & $\begin{array}{l}\text { Average velocity measured in a straight line from beginning to } \\
\text { end of track }\end{array}$ \\
\hline Curvilinear velocity & VCL & $\mu \mathrm{m} / \mathrm{sec}$ & $\begin{array}{l}\text { Average velocity measured over the actual point to point track } \\
\text { followed by the sperm }\end{array}$ \\
\hline Amplitude of lateral head displacement & ALH & $\mu \mathrm{m}$ & $\begin{array}{l}\text { Mean overall sperm tracks of twice the maximum displacement } \\
\text { between each sperm and its average path }\end{array}$ \\
\hline Beat cross frequency & $\mathrm{BCF}$ & $\mathrm{Hz}$ & $\begin{array}{l}\text { Frequency of sperm head crossing the sperm average path in } \\
\text { either direction }\end{array}$ \\
\hline Straightness & STR & $\%$ & $\begin{array}{l}\text { Departure of the sperm path from a straight line } \\
\text { Average value of the ratio VSL/VAP }(\text { VSL/VAP } \times 100)\end{array}$ \\
\hline Linearity & LIN & $\%$ & $\begin{array}{l}\text { Departure of the sperm track from a straight line } \\
\text { Average value of the ratio VSL/VCL }(\text { VSL/VCL } \times 100)\end{array}$ \\
\hline Area & Area & $\mu \mathrm{m}^{2}$ & Mean area of sperm head \\
\hline
\end{tabular}


tids and Sertoli cells (Leblond and Clermont, 1952). The data were expressed as the numbers of germ cells per Sertoli cells per seminiferous tubule cross section.

\section{Termination of female animals with successful copulation}

All female animals with successful copulation were euthanized by carbon dioxide asphyxiation on the morning of postcoitum day 20 . The ovaries and uterus from each dam were removed and the number of corpora lutea and the number of implantation sites were counted. Intrauterine distributions of the live fetuses or the type of dead embryos/fetuses (implantation trace, placental remnant, macerated fetus or dead fetus) were recorded. The fetal and placental weights were measured. Females without implantations or resorptions were classified as non-pregnant.

\section{Statistical analysis}

Data and indices were compared between each group. Various values were processed and analyzed for each animal or group. Data from one male animal without successful copulation at 8 weeks of age were excluded from the evaluation of several endpoints because it was not clear why the animal could not success the copulation. A Fischer's exact test was used to analyze the indices of male successful copulation, fertility and fetal sex ratio. Organ weights, CASA parameters, sperm count, sperm morphology and staging analysis in the testis were tested using $\mathrm{F}$ test. When there was homogenous variation of data among the groups, Student's t test was performed. When variation among the groups was not homogenous, Aspin-Welch's $t$ test was performed. The implantation index (preimplantation loss) and the embryo-fetal mortality (postimplantation loss) were determined for each litter and were compared by Wilcoxon's rank-sum test. A $p$ value $<0.05$ was considered to indicate significant difference in all statistical analyses.

\section{RESULTS}

\section{Copulatory behavior and fertility index}

No differences were observed in the copulation index between three groups. All of male animals except for one male animal in the 8-week-old group successfully copulated with the co-habited female on the first occasion. One male animal in the 8-week-old group failed to copulate during both of the first and the second cohabitation. Fertility index showed tendency toward an increase with male's age at the time of mating, $75 \%, 92.3 \%$ and $100 \%$ at 8,10 and 12 weeks of age, respectively (Table 3).
The examination of copulatory plugs resulted in agedependent changes (Table 4). The mean number and the mean weight of copulatory plugs in the 8-week-old group were lower than these indices in the 10- and 12-week-old group with or without statistical significance.

\section{Reproductive organ weight}

Except for testes, the absolute organ weight of epididymides, seminal vesicle and prostate increased in an age-dependent manner between 8-week-old and 12-weekold (Table 5-1). The absolute weight of testes increased slightly between 8 and 10 weeks of age but then reached a plateau and did not increase further at 12 weeks of age. The organ weights relative to the final body weight of epididymides, seminal vesicle and prostate resulted in an age-dependent increase, while testes decreased in an age dependent manner (Table 5-2).

\section{Sperm motion analysis}

The HTM-IVOS generated data for cauda epididymal sperm motility and motion parameters are summarized in Table 6. The percentage of motile sperm in 8-week-old male animals was substantially lower when comparing with these percentages in the 10- and 12-week-old male animals. Three vigor parameters (VCL, ALH and BCF) were similar manner among the three groups. In addition to the above vigor parameters, 4 progression parameters (VAP, VSL, STR and LIN) were measured. Although there were slight differences among the three groups, there was no age dependent trend. Mean area of sperm head was also comparable in each group.

\section{Sperm count}

The number of sperm in the caput and caudal region of the left epididymis and the spermatid head count for the left testis are summarized in Table 7. The number of sperm in the cauda epididymis increased age-dependently with or without statistical significance, whereas the number of sperm in the caput region increased with statistical significance between 8 and 10 weeks of age but then plateaued between 10 and 12 weeks of age. Testicular spermatid head count also showed a statistically significant increase with age-dependency (Table 7).

\section{Sperm morphology}

The number of sperm with morphological abnormalities and the types of abnormalities are summarized in Table 8 and Fig. 1. In the 8-week-old group, the total number of morphologically abnormal sperm was significantly higher than the other two groups. Tailless sperm constituted the most common abnormality but neck 
Suitable age of Wistar Han male rats for DART study

Table 3. Reproductive performance of male rats

\begin{tabular}{lccc}
\hline Group & Number of pairs & Copulation index (\%) a) & Fertility index (\%) b) \\
\hline 8-week-old & 13 & 92.3 & 75.0 \\
& & $(12 / 13)$ & $(9 / 12)$ \\
10-week-old & 13 & 100.0 & $(12.3$ \\
& & $(13 / 13)$ & 100.0 \\
12-week-old & 13 & 100.0 & $(13 / 13)$ \\
\hline
\end{tabular}

a): Copulation index $=($ No. of male animals with successful copulation $) /($ No. of male animals cohabited $) \times 100$.

b): Fertility index $=($ No. of males impregnating females $) /($ No. of males with successful copulation $) \times 100$.

Table 4. Number and weights of copulatory plugs

\begin{tabular}{lccc}
\hline Group & No. of animals examined & Mean number & Mean weight \\
\hline 8-week-old & $12^{\mathrm{a}}$ & $1.4 \pm 0.5^{* * \$ \$ \$}$ & $23.3 \pm 10.0 *$ \\
10-week-old & $13^{\mathrm{a}}$ & $2.8 \pm 1.4$ & $25.2 \pm 13.0$ \\
12-week-old & $12^{\mathrm{b}}$ & $3.7 \pm 1.4$ & $39.4 \pm 22.2$ \\
\hline
\end{tabular}

Each value represents mean \pm S.D.

a): Including non-gravid animals.

b): Nevertheless the successful copulation was confirmed, no copulatory plugs were collected from one animal.

*: Significantly different from 12 -week-old group, t-test, **; $\mathrm{P}<0.01, * ; \mathrm{P}<0.05$.

$\$$ : Significantly different from 10 -week-old group, t-test, $\$$; $; \mathrm{P}<0.01$.

Table 5-1. Absolute organ weights of male animals

\begin{tabular}{|c|c|c|c|c|c|c|}
\hline Group & No. of animals & Final body weight & Epididymides & Testes & Seminal vesicle & Prostate \\
\hline 8-week-old & $12^{\mathrm{a})}$ & $245.0 \pm 11.0 * *, \$ \$$ & $0.571 \pm 0.059 * *, \$ \$$ & $2.923 \pm 0.165 * *, s s$ & $0.315 \pm 0.053 * *, \$ \$$ & $0.374 \pm 0.073^{* *, \$ \$}$ \\
\hline 10-week-old & $13^{\mathrm{b})}$ & $304.6 \pm 8.8 * *$ & $0.896 \pm 0.075^{* *}$ & $3.414 \pm 0.283$ & $0.499 \pm 0.083 * *$ & $0.513 \pm 0.108$ \\
\hline 12-week-old & 13 & $334.0 \pm 6.2$ & $1.087 \pm 0.067$ & $3.405 \pm 0.208$ & $0.654 \pm 0.052$ & $0.633 \pm 0.108$ \\
\hline
\end{tabular}

Data are shown as mean \pm S.D., Unit: gram

a): Included three infertile animals b): Included one infertile animal.

*: Significantly different from 12-week-old group, t-test, **; P $<0.01$ s: Significantly different from 10-week-old group, t-test, ss; $\mathrm{P}<0.01$

Table 5-2. Relative organ weights in male rats

\begin{tabular}{lccccc}
\hline Group & No. of animals & Epididymides & Testes & Seminal vesicle & Prostate \\
\hline 8-week-old & $12^{\text {a) }}$ & $2.33 \pm 0.22^{* *, \$ \$}$ & $11.94 \pm 0.51^{* *, \$ \$}$ & $1.29 \pm 0.24 * *, \$ \$$ & $1.52 \pm 0.29 * *$ \\
10-week-old & $13^{\text {b) }}$ & $2.94 \pm 0.21^{* *}$ & $11.21 \pm 0.86^{*}$ & $1.64 \pm 0.27^{* *}$ & $1.68 \pm 0.34$ \\
12-week-old & 13 & $3.26 \pm 0.20$ & $10.20 \pm 0.70$ & $1.96 \pm 0.15$ & $1.90 \pm 0.35$ \\
\hline
\end{tabular}

Each value is represented as gram per kilogram.

Data are shown as mean \pm S.D. a): Included three infertile animals b): Included one infertile animal.

*: Significantly different from 12 -week-old group, t-test, *; $\mathrm{P}<0.05, * * ; \mathrm{P}<0.01$.

$\$$ : Significantly different from 10 -week-old group, t-test, $\$$; $; \mathrm{P}<0.01$.

abnormalities were also relatively high in this group. The incidence of sperm with head abnormalities was also increased in the 8- and 10-week-old groups when compared with the 12-week-old animals.

\section{Histological changes in male reproductive organs}

The results of histological observation were summarized in Table 9. There were no histological abnormalities 
Table 6. Sperm motion analysis

\begin{tabular}{lccc}
\hline Parameter & 8-week-old & 10-week-old & 12-week-old \\
\hline Number of animals examined & $12^{\mathrm{a}) \text {, b) }}$ & $13^{\mathrm{c})}$ & 13 \\
Motile sperm $(\%)$ & $46.5 \pm 17.5^{* *, \$ \$}$ & $75.4 \pm 6.8$ & $73.5 \pm 11.9$ \\
VAP $(\mu \mathrm{m} / \mathrm{sec})$ & $141.1 \pm 10.6^{\$}$ & $133.0 \pm 5.3$ & $136.2 \pm 9.0$ \\
VSL $(\mu \mathrm{m} / \mathrm{sec})$ & $96.3 \pm 10.9^{*}$ & $90.7 \pm 5.2$ & $86.8 \pm 8.5$ \\
VCL $(\mu \mathrm{m} / \mathrm{sec})$ & $325.1 \pm 22.9^{\$}$ & $301.4 \pm 19.8$ & $303.3 \pm 30.3$ \\
ALH $(\mu \mathrm{m})$ & $16.4 \pm 2.0$ & $16.1 \pm 1.2$ & $16.8 \pm 2.7$ \\
BCF $(\mathrm{Hz})$ & $32.3 \pm 2.6^{\text {Ss }}$ & $29.0 \pm 3.1$ & $31.0 \pm 2.7$ \\
STR $(\%)$ & $69.3 \pm 6.7$ & $69.8 \pm 3.3$ & $66.1 \pm 6.3$ \\
LIN $(\%)$ & $32.6 \pm 3.8$ & $32.5 \pm 2.5$ & $31.1 \pm 3.1$ \\
Area $\left(\mu \mathrm{m}^{2}\right)$ & $154.1 \pm 33.5$ & $156.9 \pm 16.3$ & $163.0 \pm 21.1$
\end{tabular}

Data are shown as mean \pm S.D.

a): One animal without successful copulation was excluded. b): Included three infertile animals. c): Included one infertile animal.

*: Significantly different from 12 -week-old group, t-test, $*$; $\mathrm{P}<0.05, * * ; \mathrm{P}<0.01$.

s: Significantly different from 10-week-old group, t-test, $\$$; $\mathrm{P}<0.05$, ss; $\mathrm{P}<0.01$.

Table 7. Number of sperm and daily sperm production

\begin{tabular}{|c|c|c|c|c|}
\hline \multirow{2}{*}{ Group } & \multirow{2}{*}{ No. of animals } & \multicolumn{2}{|c|}{ No. of sperm in epididymis $\left(\times 10^{6} / \mathrm{g}\right)$} & \multirow{2}{*}{$\begin{array}{l}\text { No. of spermatids in testis } \\
\qquad\left(\times 10^{6} / \mathrm{g}\right)\end{array}$} \\
\hline & & Caput & Cauda & \\
\hline 8-week-old & $12^{\mathrm{a}), \mathrm{b})}$ & $177.4 \pm 23.6^{* *, \$ s}$ & $141.8 \pm 71.1^{* *, \$ \$}$ & $76.1 \pm 24.0^{* *, \$ \$}$ \\
\hline 10-week-old & $13^{c)}$ & $259.4 \pm 46.6$ & $247.6 \pm 74.2$ & $104.5 \pm 21.5^{* *}$ \\
\hline 12-week-old & 13 & $246.0 \pm 44.9$ & $287.3 \pm 76.1$ & $135.1 \pm 20.3$ \\
\hline
\end{tabular}

Data are shown as mean \pm S.D.

a): One animal without successful copulation was excluded. b): Included three infertile animals. ${ }^{c}$ : Included one infertile animal.

*: Significantly different from 12-week-old group, t-test, $* *: \mathrm{P}<0.01$.

$\$$ : Significantly different from 10 -week-old group, t-test, $\$$ : $\mathrm{P}<0.01$.

in the cell components and the structure of testes in all animals in the different age groups. Immature epididymides were observed in all males of the 8-week-old group. The lumens of the cauda epididymal ducts appeared small and the ductal epithelium appeared thicker and pseudostratified in the 8-week-old rats, while the large ducts with large lumens and lined by cuboidal to columnar simple epithelium in the 10- and 12-week-old rats (Fig. 2). In addition, cell debris in the ducts of caput and cauda epididymides was present with a high proportion in the 8-week-old males. A few cell debri was observed in the epididymides of only two males from the 10- and 12 -week-old groups. In the seminal vesicle and prostate, interstitial inflammatory cell infiltration was observed to an equal degree in all groups. Therefore, this finding was not considered to be an age-dependent.

\section{Quantitative examination of spermatogenic cells (Staging analysis of testicular semiferous tubules)}

Quantitative analysis of spermatogenic cells was performed using sections stained by the PAS reaction. The results are shown in Table 10. There appeared to be a slight increase related with age in the number of spermatogonia in stages V, VII and XII, with statistical significance in the stage VII spermatogonia. Although there were occasional statistically significant differences in zygotene and pachytene spermatocyte counts, there was no apparent tendency related with age, and these differences were considered to be incidental.

\section{Male fertility}

Female animals with successful copulation were euthanized in the morning on gestation day 20 (postcoitum day 20). Ovaries and uterus in each dam were examined 
Suitable age of Wistar Han male rats for DART study

Table 8. Content of morphologically abnormal sperm in cauda epididymis

\begin{tabular}{lccccccc}
\hline Group & $\begin{array}{c}\text { No. of } \\
\text { animals }\end{array}$ & Tailless (\%) & $\begin{array}{c}\text { Head } \\
\text { abnormalities } \\
(\%)\end{array}$ & $\begin{array}{c}\text { Neck } \\
\text { abnormalities } \\
(\%)\end{array}$ & $\begin{array}{c}\text { Tail } \\
\text { abnormalities } \\
(\%)\end{array}$ & Others (\%) & Total (\%) \\
\hline 8-week-old & $12^{\mathrm{a}) \text {, b) }}$ & $3.2 \pm 1.5^{* *, \$ \$}$ & $1.4 \pm 1.6$ & $1.0 \pm 1.3$ & $0.0 \pm 0.0$ & $0.0 \pm 0.0$ & $5.6 \pm 3.1^{* *, \$ s}$ \\
10-week-old & $13^{\mathrm{c})}$ & $0.9 \pm 1.1$ & $1.1 \pm 0.8^{*}$ & $0.2 \pm 0.4$ & $0.0 \pm 0.0$ & $0.0 \pm 0.0$ & $2.2 \pm 1.2$ \\
12-week-old & 13 & $0.9 \pm 0.8$ & $0.5 \pm 0.5$ & $0.3 \pm 0.4$ & $0.0 \pm 0.0$ & $0.0 \pm 0.0$ & $1.7 \pm 1.1$ \\
\hline
\end{tabular}

Data are shown as mean \pm S.D.

a): One animal without successful copulation was excluded. b): Included three infertile animals. c): Included one infertile animal.

*: Significantly different from 12-week-old group, t-test, **: $\mathrm{P}<0.01, *$ : $\mathrm{P}<0.05$.

$\$$ : Significantly different from 10 -week-old group, t-test, $\$$ : $\mathrm{P}<0.01$.

Table 9. Histological findings in male reproductive organs

\begin{tabular}{|c|c|c|c|c|c|c|c|}
\hline \multirow[b]{2}{*}{ Group } & Organ & Testis & \multicolumn{3}{|c|}{ Epididymis } & \multirow{2}{*}{$\begin{array}{c}\text { Seminal vesicle } \\
\text { Inflammatory cell } \\
\text { infiltration, interstitial }\end{array}$} & \multirow{2}{*}{$\begin{array}{c}\text { Prostate } \\
\text { Inflammatory cell } \\
\text { infiltration, interstitial }\end{array}$} \\
\hline & Findings & - & Immature & $\begin{array}{c}\text { Cell debris, } \\
\text { Caput }\end{array}$ & $\begin{array}{l}\text { Cell debris, } \\
\text { Cauda }\end{array}$ & & \\
\hline 8-week-olda), b) & & - & $\begin{array}{c}100.0 \\
(12 / 12)\end{array}$ & $\begin{array}{c}46.2 \\
(6 / 12)\end{array}$ & $\begin{array}{c}69.2 \\
(9 / 12)\end{array}$ & $\begin{array}{c}41.7 \\
(5 / 12)\end{array}$ & $\begin{array}{c}25.0 \\
(3 / 13)\end{array}$ \\
\hline 10-week-oldc) & & - & $\begin{array}{c}0.0 \\
(0 / 13)\end{array}$ & $\begin{array}{c}15.4 \\
(2 / 13)\end{array}$ & $\begin{array}{c}7.7 \\
(1 / 13)\end{array}$ & $\begin{array}{c}69.2 \\
(9 / 13)\end{array}$ & $\begin{array}{c}30.8 \\
(4 / 13)\end{array}$ \\
\hline 12-week-old & & - & - & $\begin{array}{c}7.7 \\
(1 / 13)\end{array}$ & $\begin{array}{c}7.7 \\
(1 / 13)\end{array}$ & $\begin{array}{c}69.2 \\
(9 / 13) \\
\end{array}$ & $\begin{array}{c}53.8 \\
(7 / 13)\end{array}$ \\
\hline
\end{tabular}

Values represent incidence (\%) and values in parentheses represent number of animals with finding / number of animals examined. a): One animal without successful copulation was excluded. b): Included three infertile animals. c): Included one infertile animal.

Table 10. Cell types and ratios to Sertoli cells in seminiferous tubles (Spermatogenic cycle staging analysis)

\begin{tabular}{|c|c|c|c|c|c|c|c|}
\hline \multirow{2}{*}{ Group } & \multirow{2}{*}{$\begin{array}{c}\text { No. of animals } \\
\text { observed }\end{array}$} & \multirow{2}{*}{ Stage } & \multicolumn{5}{|c|}{ Number of germ cells / Sertoli cells } \\
\hline & & & Spermatogonia & Preleptotene & Zygotene & Pachytene & Round \\
\hline \multirow{4}{*}{$\begin{array}{l}\text { 8-week- } \\
\text { old }\end{array}$} & \multirow{4}{*}{5} & II-III & $0.85 \pm 0.07$ & - & - & $2.39 \pm 0.10$ & $7.05 \pm 0.70$ \\
\hline & & $\mathrm{V}$ & $1.72 \pm 0.14$ & - & - & $2.78 \pm 0.14^{\$ \$}$ & $7.63 \pm 0.75^{s}$ \\
\hline & & VII & $0.22 \pm 0.03 * *$ & $1.88 \pm 0.36$ & - & $2.98 \pm 0.40$ & $8.17 \pm 0.56$ \\
\hline & & XII & $0.28 \pm 0.04$ & - & $2.18 \pm 0.15^{*}$ & $2.87 \pm 0.26$ & - \\
\hline \multirow{4}{*}{$\begin{array}{l}\text { 10-week- } \\
\text { old }\end{array}$} & \multirow{4}{*}{5} & II-III & $0.87 \pm 0.20$ & - & - & $2.47 \pm 0.13$ & $7.03 \pm 0.94$ \\
\hline & & $\mathrm{V}$ & $1.77 \pm 0.16$ & - & - & $2.44 \pm 0.15^{* *}$ & $6.52 \pm 0.70$ \\
\hline & & VII & $0.25 \pm 0.03 * *$ & $1.63 \pm 0.20$ & - & $2.76 \pm 0.28$ & $7.52 \pm 0.95$ \\
\hline & & XII & $0.31 \pm 0.05$ & - & $2.07 \pm 0.13^{* *}$ & $2.75 \pm 0.24^{*}$ & - \\
\hline \multirow{4}{*}{$\begin{array}{l}\text { 12-week- } \\
\text { old }\end{array}$} & \multirow{4}{*}{5} & II-III & $0.85 \pm 0.08$ & - & - & $2.37 \pm 0.14$ & $6.40 \pm 0.41$ \\
\hline & & V & $1.84 \pm 0.21$ & - & - & $2.84 \pm 0.22$ & $7.18 \pm 0.49$ \\
\hline & & VII & $0.30 \pm 0.04$ & $1.81 \pm 0.14$ & - & $3.12 \pm 0.23$ & $8.00 \pm 0.63$ \\
\hline & & XII & $0.33 \pm 0.03$ & - & $2.36 \pm 0.07$ & $3.06 \pm 0.15$ & - \\
\hline
\end{tabular}

Each data represents the mean \pm S.D.

*: Significantly different from 12-week-old group, t-test, $* *: \mathrm{P}<0.01, *: \mathrm{P}<0.05$.

$\$$ : Significantly different from 10 -week-old group, t-test, $\$$ s: $\mathrm{P}<0.01, \$: \mathrm{P}<0.05$. 
I. Takakura et al.
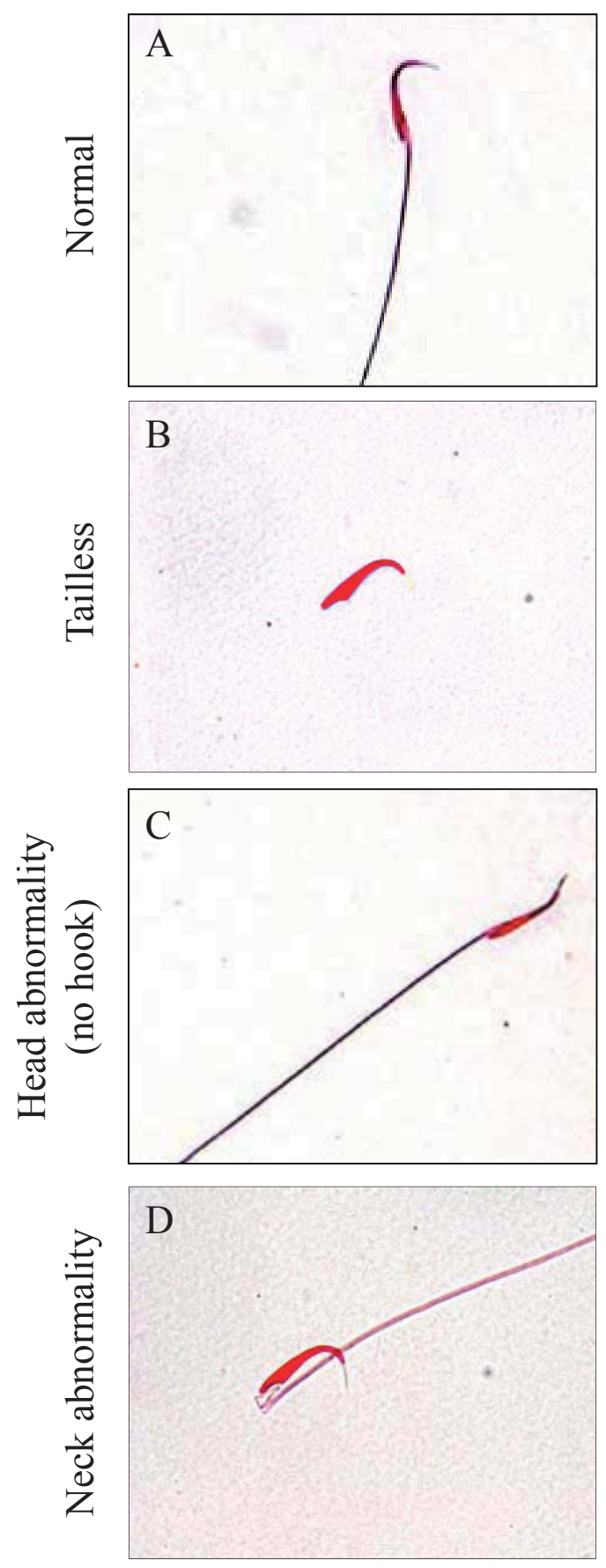

Fig. 1. Micrographs of representative sperm from the cauda epididymis of 8-week-old group. Sperm suspension from cauda epididymis was stained with $0.5 \%$ Eosin $\mathrm{Y}$ and 200 sperm in each animal were examined microscopically for head, neck and tail morphological abnormalities. A: Normal sperm. B: Tailless sperm. C: Sperm with head abnormality (no hook). D: Sperm with neck abnormality (flection in the neck region). A-D: $\times 400$.
(Table 11). The number of implantation sites showed statistically significant differences in dams fertilized by an 8-week-old male rat when compared with dams fertilized by a 12 -week-old male rat. On the other hand, it was similar between 10- and 12-week-old groups in the number of implantation sites. Preimplantation loss of the 8-weekold group resulted in significantly high incidence. Especially, five out of nine dams showed $50 \%$ or more preimplantation loss in the 8-week-old group. Additionally, a significant increase in the preimplantation loss resulted in a statistically significant decrease in the number of live fetuses in dams fertilized by a male rat in the 8-week-old group when compared with these parameters in dams fertilized by a male rat in the 12 -week-old group. There were no age-dependent effects on the number of dead fetuses, postimplantation loss, fetal sex ratio, fetal weight or placental weight.

\section{DISCUSSION}

The present study demonstrated the progressive maturation in copulatory behavior, fertility and sperm production in male Wistar Han rats from 8 to 12 weeks of age.

In the present study, epididymal sperm were assessed for number, motility (vigor and progression parameters) and morphology. In addition, cell types and ratios to Sertoli cells in testicular seminiferous tubules were analysed. There was an age-related statistical increase in the number of spermatogonia in seminiferous tubules and total number of sperm in the testis from 8 through to 12 weeks of age. It certainly means the increase of the activity of the spermatid maturation in seminiferous tubules from 8 -week-old to 12 -week-old. This correlated with increased numbers of sperm in the epididymis, especially in the cauda epidydimis. Motility (\% motile) of sperm in the caput and cauda epidydimis showed significantly low values in the 8 -week-old animals but these values reached those of adult males and plateaued by 10 weeks of age. The findings of low sperm number, low motility and increased abnormal sperm likely contributed to the low fertility index in the 8-week-old male rats. Shimomura et al. (2008) reported a decreased incidence of headless sperm in urine and epididymis from male Sprague Dawley rats from 8 to 12 weeks of age in parallel with sexual maturation. In Sprague Dawley rats, serum testosterone level began to increase at about 3 weeks of age and continue to rise until adult levels at about 10 weeks of age (Korenbrot et al., 1977; Chan et al., 1981). On the other hand, serum testosterone increased from 7 weeks of age and was maximal at 13 weeks of age in Wistar rats (Umezu et al., 2004). Together with these reports, 
Suitable age of Wistar Han male rats for DART study

Table 11. Results of cesarean section of dams

\begin{tabular}{|c|c|c|c|c|}
\hline Dam & & 8-week-old & 10-week-old & 12-week-old \\
\hline Number of dams evaluated & & 9 & 12 & 13 \\
\hline Number of corpora lutea & & $13.89 \pm 1.45$ & $14.17 \pm 1.19$ & $13.46 \pm 1.45$ \\
\hline Number of implantation & & $7.89 \pm 4.88^{*}$ & $12.25 \pm 2.30$ & $12.23 \pm 1.59$ \\
\hline Preimplantation loss (\%) & & $43.98 \pm 31.92^{\# \#}$ & $13.60 \pm 13.97$ & $8.70 \pm 11.17$ \\
\hline Number of dead embryos/fetuses & & $0.44 \pm 0.88$ & $0.58 \pm 0.67$ & $0.85 \pm 0.69$ \\
\hline Postimplantation loss (\%) & & $3.07 \pm 6.09$ & $4.91 \pm 6.01$ & $7.12 \pm 5.90$ \\
\hline Number of live fetuses & & $7.44 \pm 4.25^{*}$ & $11.67 \pm 2.35$ & $11.38 \pm 1.80$ \\
\hline Fetal sex ratio (Male/Female) & & $0.68(27 / 40)$ & $1.19(76 / 64)$ & $0.74(63 / 85)$ \\
\hline \multirow{3}{*}{ Fetal body weight (g) } & Male & $3.45 \pm 0.16$ & $3.51 \pm 0.23$ & $3.58 \pm 0.18$ \\
\hline & Female & $3.30 \pm 0.24$ & $3.35 \pm 0.19$ & $3.42 \pm 0.15$ \\
\hline & Total & $3.37 \pm 0.21$ & $3.42 \pm 0.19$ & $3.47 \pm 0.15$ \\
\hline \multirow{3}{*}{ Placental weight (g) } & Male & $0.532 \pm 0.087$ & $0.478 \pm 0.049$ & $0.487 \pm 0.044$ \\
\hline & Female & $0.521 \pm 0.088$ & $0.473 \pm 0.061$ & $0.491 \pm 0.038$ \\
\hline & Total & $0.531 \pm 0.085$ & $0.477 \pm 0.053$ & $0.489 \pm 0.038$ \\
\hline
\end{tabular}

*: Significantly different from females paired with 12 -week-old group, t-test, *: $\mathrm{P}<0.05$.

\# : Significantly different from females paired with 12 -week-old group, Wilcoxon rank-sum test, \#\#: $\mathrm{P}<0.01$.

the current study suggests that there might be an age-related difference in testosterone production between the two strains and this difference would affect the timing of sperm maturation.

The epididymal epithelium of all 8-week-old rats had an immature appearance, characterized by ducts with smaller lumens which were lined by a thicker and pseudostratified epithelium when compared with the epididymis in the 10- and 12-week-old rats. Increased cell debris (representing sloughed germ cells from the testis and epithelial cells from the maturing epididymis) were also seen in the epididymis of most of the 8-weekold rats. The epididymis is responsible for maturation of sperm and for the elimination of defective sperm (Hinton et al., 1996). The lack of structural maturity of the epididymis suggests that they may be lack of functional maturity of the epididymis.

Fertility index of the 8 -week-old group decreased compared with that of 10 - and 12 -week-old males. The examination of copulatory plugs of the 8-week-old group showed remarkable low values in the mean number and the mean weight when compared with the other age groups. The copulatory plug is formed by the coagulation of the secretions from the seminal vesicles and coagulating glands at the time of ejaculation (Carballada and Esponda, 1992). The lower weight and reduced number of copulatory plugs in the 8 -week-old males correlated with the lower weight (likely representing lower secretory content) of the seminal vesicles. Successful transcervical transport of sperm has been shown to be heavily dependent on a tightly fitting copulatory plug being deposited in the vagina in close juxtaposition with the cervix (Reynolds et al., 2010). It is possible that the decreased copulatory plug size and number in the 8-week-old group contributed to the observed decreased fertility index and increase in preimplantation loss when compared with 10or 12-week-old male animals.

The weight of the reproductive organs except for testes, showed an age-related increase both in absolute and relative weight. The absolute weight of testes seemed to have reached a plateau by 10 weeks of age. On the other hand, their body weight continued to increase between the 8 and 12 weeks of ages. Then, the testis weight relative to the body weight was decreased age-dependently.

There were no age-related changes in the testis that could be detected by qualitative evaluation. Although the absolute weight of the testis and testicular spermatid head count were lower in the 8-week-old rats than 10- and 12-week-old rats, the qualitative size of the seminiferous tubules and the sperm maturation histologically appeared similar in the testes from the different age groups. Because testicular spermatid head count showed an age-related increase from 8 to 12 weeks of ages, the efficiency of testicular spermatogenesis must have been 


\section{Takakura et al.}
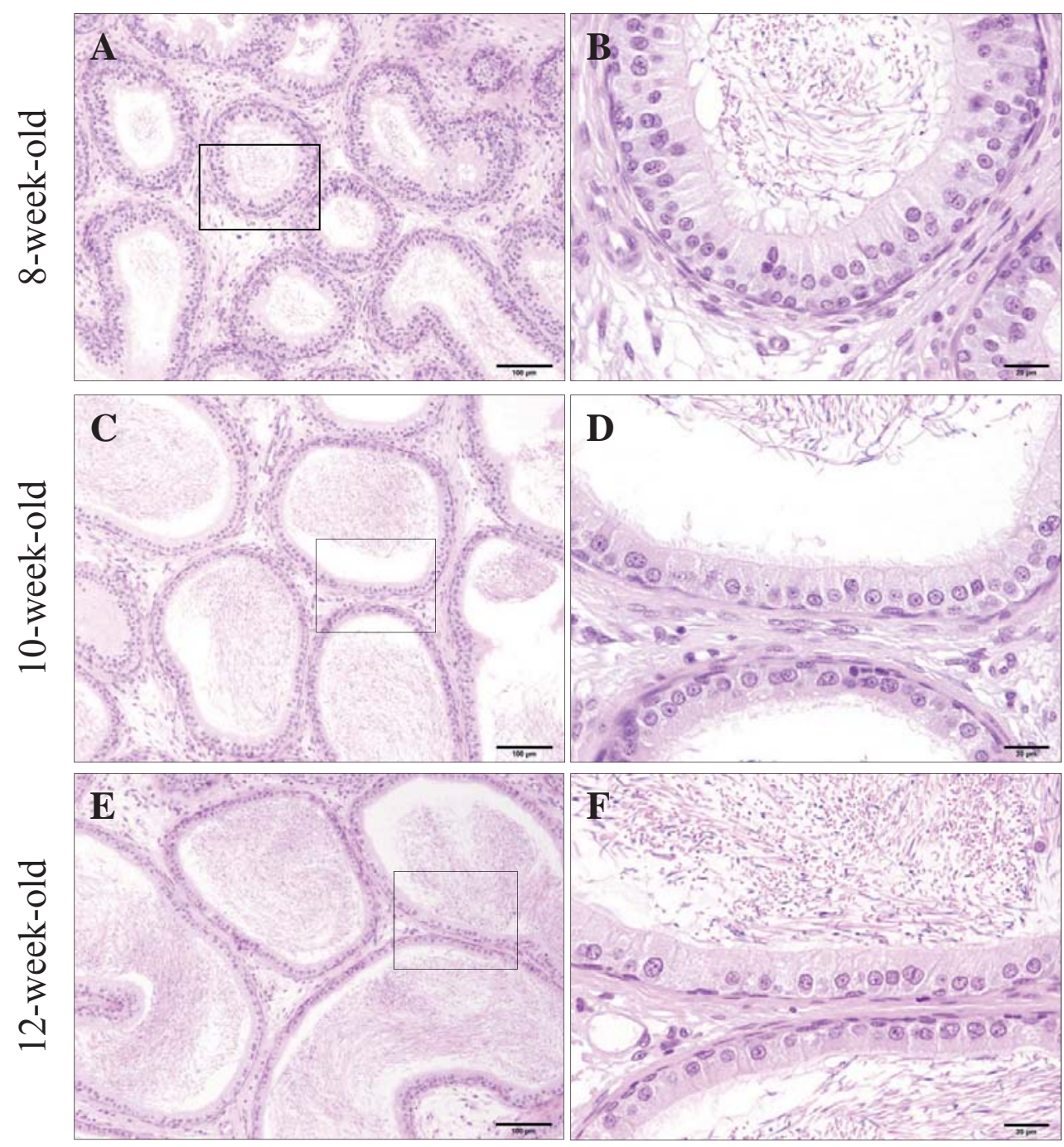

Fig. 2. Histological changes in epididymal ducts and ductal epithelium. Left epididymis was processed to paraffin-embedded sections and stained with hematoxylin and eosin. The lumens of the epididymal ducts appeared smaller and the ductal epithelium appeared thicker in the 8-week-old rats. A and B: 8-week-old group. C and D: 10-week-old group. E and F: 12-weekold group. The boxed areas in A, C and E are shown in B, D and F at higher magnification, respectively. Bars: A, C and $\mathrm{E} ; 100 \mu \mathrm{m}, \mathrm{B}, \mathrm{D}$ and $\mathrm{F} ; 20 \mu \mathrm{m}$.

increasing. Apart from the age-related increase in sperm numbers, increased spermatogenesis was not detectable by either qualitative or quantitative evaluation of germ cell numbers.

Cesarean section in dams revealed that the mean number of live fetuses was significantly less in the dams mated to 8-week-old males (7.4) when compared with 10or 12-week-old males ( $>11$ fetuses for both groups). The decrease in fetuses was largely explained by a significant increase in the incidence of preimplantation loss in dams paired with a 8 -week-old male. There were no differences in fetal body weights or fetal sex ratio between the different groups. For reproductive toxicity studies in rats, at least 10 live pups per litter is desirable in order to evaluate any adverse effects on fetal development appropriately and therefore the litter size produced by the 8-weekold males was considered inadequate. King-Herbert et al. (2010) reported that Wistar Han rats that were time-mated at the animal supplier and then shipped into the National Toxicology Program facility produced small litter sizes 
Suitable age of Wistar Han male rats for DART study

(8.2 pups/litter). In the current study, 12-week-old males produced litter sizes $>10$ pups/litter and there are no concerns for evaluation for the adverse effects on fetuses.

Based on the reproductive endpoints examined, most of the parameters had plateaued and reached adult values by 10 weeks of age. However, certain parameters such as testicular sperm production and weight of the epididymis, accessory sex organs and copulatory plugs continued to increase up to 12 weeks of age. These developing endpoints could have possibility producing unstable data in the DART study and affect the correct evaluation for adverse effects on reproductive function of newly developing compounds.

In conclusion, we would recommend that male Wistar Han rats at 12 weeks old or older be used for conducting DART studies in order to properly evaluate any adverse effects on reproductive function and embryo-fetal development.

\section{REFERENCES}

Campion, S.N., Carvallo, F.R., Chapin, R.E., Nowland, W.S., Beauchamp, D., Jamon, R., Koitz, R., Winton, T.R., Cappon, G.D. and Hurtt, M.E. (2013): Comparative assessment of the timing of sexual maturation in male Wistar Han and SpragueDawley rats. Reprod. Toxicol., 38, 16-24.

Carballada, R. and Esponda, P. (1992): Role of fluid from seminal vesicles and coagulating glands in sperm transport into the uterus and fertility in rats. J. Reprod. Fertil., 95, 639-648.

Chan, V., Clayton, R.N., Knox, G. and Catt, K.J. (1981): Ontogeny of pituitary GnRH receptors in the rat. Endocrinology, 108, 2086-2092.

Hinton, B.T., Palladino, M.A., Rudolph, D., Lan, Z.J. and Labus, J.C. (1996): The role of the epididymis in the protection of spermatozoa. Curr. Top Dev. Biol., 33, 61-102.

King-Herbert, A.P., Sills, R.C. and Bucher, J.R. (2010): Commentary: update on animal models for NTP studies. Toxicol. Pathol., 38, 180-181.

Klinefelter, G.R., Gray, L.E.Jr. and Suarez, J.D. (1991): The method of sperm collection significantly influences sperm motion parameters following ethane dimethanesulphonate administration in the rat. Reprod. Toxicol., 5, 39-44.

Korenbrot, C.C., Huhtaniemi, I.T. and Weiner, R.I. (1977): Preputial separation as an external sign of pubertal development in the male rat. Biol. Reprod., 17, 298-303.

Kuze, T. (1997): Comparison of various fixatives on rat testis. Jpn. J. Histotech., 6, 17-22.

Leblond, C.P. and Clermont, Y. (1952): Definition of the stages of the cycle of the seminiferous epithelium in the rat. Ann. NY Acad. Sci., 55, 548-573.

Linder, R.E., Strader, L.F., Slott, V.L. and Suarez, J.D. (1992): Endpoints of spermatotoxicity in the rat after short duration exposures to fourteen reproductive toxicants. Reprod. Toxicol., 6, 491-505.

Matsui, H., Toyoda, K., Kawanishi, T., Mitsumori, K., Takahashi, M., Fukuhara, K. and Miyata, N. (1996): Advantages of simplified quantitative morphometry using stage grouping analysis of spermatogenic cycle for evaluation of the testicular toxicity of Ethylene-1,2-dimethanesulfonate in rats. J. Toxicol. Pathol., 9, 285-292.

Reynolds, V.L., Stump, D.G. and Holson, J.F. (2010): Assessing the toxicological significance of ejaculatory plugs as a clinical observation in rat toxicology studies: CNS-mediated increases in plug production vs. gustatory-mediated decreases in plug consumption. Reprod. Toxicol., 29, 271-278.

Shimomura, K., Sakurai, K., Shimada, M., Hagiwara, M., Kato, M. and Furuhama, K. (2008): Occurrence of headless sperm in adolescent rat urine. Lab. Anim., 42, 204-212.

Umezu, M., Kagabu, S., Jiang, J.Y., Niimura, S. and Sato, E. (2004): Developmental hormonal profiles in rdw rats with congenital hypothyroidism accompanying increased testicular size and infertility in adulthood. J. Reprod. Dev., 50, 675-684.

Weber, K., Razinger, T., Hardisty, J.F., Mann, P., Martel, K.C., Frische, E.A., Blumbach, K., Hillen, S., Song, S.W., Anzai, T. and Chevalier, H.J. (2011): Differences in rat models used in routine toxicity studies. Int. J. Toxicol., 30, 162-173.

Wyrobek, A.J. and Bruce, W.R. (1975): Chemical induction of sperm abnormalities in mice. Proc. Natl. Acad. Sci. USA., 72, 4425-4429.

Yoshizaki, H., Izumi, Y., Hirayama, C., Fujimoto, A., Kandori, H., Sugitani, T. and Ooshima, Y. (1999): Availability of sperm examination for male reproductive toxicities in rats treated with boric acid. J. Toxicol. Sci., 24, 199-208. 